\title{
The Role of Analog Publications in a Digital World
}

\author{
The Archaeological Case Study Celsus
}

Nicole M. High-Steskal

\begin{abstract}
Austrian Archaeological Institute of the Austrian Academy of Sciences nicole.high-steskal@oeai.at

https://www.oeaw.ac.at/oeai/das-institut/team/zentrale-wien/high-steskal-nicole/, https://orcid.org/0000-0002-9823-5507
\end{abstract}

Keywords: Archaeology, Urban Gazetteer, Linked Open Data, Open Access, Ephesos

\begin{abstract}
CELSUS is an archaeological digitization project focused on the creation of a spatially driven digital edition of the monograph series Forschungen in Ephesos (FiE), a publication series edited by the Austrian Archaeological Institute (OeAl). It was first started in 1906 and represents the most important results of the Austrian excavations in Ephesos to date. However, many of the older volumes no longer are available and the series is difficult to use for individuals unfamiliar with the long research history of Ephesos. Yet, the information in these volumes is of considerable interest to scholars because they document all archaeological engagement with the monuments and people of the area, often provide detailed descriptions of the landscape, including of remains that no longer are visible, furthermore, they include full catalogs of all finds, and, therefore, constitute primary evidence for all studied contexts and finds in Ephesos.
\end{abstract}

The ancient city of Ephesos, an archaeological site located along the western coast of modern-day Turkey, has been the object of intense study by the Austrian Archaeological Institute since $1895 .{ }^{1}$ The past 125 years have led to the accumulation of extremely large quantities of information from a single archaeological site. The collected information documents human engagement with the geographic location from the $6^{\text {th }}$ millennium BCE to the modern period with a specific focus on the $7^{\text {th }}$ century BCE to the $14^{\text {th }}$ century CE. The bulk of the information collected up until the late 1990 s is analog while the first digital data were created in the 1990s and has increased over the years. ${ }^{2}$ The information has been documented in a variety of formats ranging from analog, digitized, to born digital. Analog information is available through the plentiful publications on Ephesos as well as the large in-house archive safeguarding the diaries of excavation directors and the documentation of the excavations encompassing

1 For an overview of the site, see: Sabine LADSTÄTTER, Hafen und Stadt von Ephesos in hellenistischer Zeit, in: Jahreshefte des Österreichischen Archäologischen Institutes 85 (2016), 233-272.

2 For the use of the terms data, dataset,... see: Adela Sовоткоva, Sociotechnical Obstacles to Archaeological Data Reuse, in: Advances in Archaeological Practice 6/2 (2018), 118; Ben MARWICK / Suzanne BIRCH, A Standard for the Scholarly Citation of Archaeological Data as an Incentive to Data Sharing, in: Advances in Archaeological Practice 6/2 (2018), 126f. 
maps, sketches, and photographs. A large part of the historic photographs has already been digitized and is available through an internal image database. A Geographic Information System was also implemented in order to better manage the spatial information documented during the excavation process.

Using this information poses several challenges. The first obvious issue is one of accessibility: the first Austrian essays on Ephesos were published in the 1890s in a limited number and only very few libraries still have a copy of these publications. Another challenge is the amount of information. The collection of data has increased exponentially over the years so that it is no longer possible for a single person to retain the information in its entirety. This has led to unfortunate situations where already documented information is "redocumented" or already studied aspects are again studied without any consideration of the previous results. The third considerable issue is that of language. Not only are the volumes largely written in complex German but over the years spelling has changed as has the evaluation of monuments. In particular, the first interpretation and naming of monuments has not always stood the test of time. Keeping track of these name changes can be a challenge to all, particularly to scholars not fully fluent in German. The consequence of these three issues is that it puts scholars at a disadvantage who do not have a solid command of German and those who do not have access to fully stocked libraries.

In order to move forward in the study of Ephesos it is necessary to manage the existing information in a more efficient way. CELSUS marks the first step of the OeAl towards making its vast collection of literature, archival material, and images openly available and we are partnering with digital humanities specialists at several institutions in Austria and Germany. In a pilot project we are focusing on the most important publication series on Ephesos, the Forschungen in Ephesos (FiE), which currently include 48 volumes. In collaboration with the Verlag der Österreichischen Akademie der Wissenschaften, we are working with Propylaeum ${ }^{3}$ of the Heidelberg University Library, a specialized information service for Classical studies and archaeology, which is scanning the entire FiE for us, supporting us in the application of automatic text recognition, and archiving the scans and associated metadata. Propylaeum follows all current best practices of Linked Open Data and implements various semantic frameworks (CIDOC-CRM) and metadata formats. Furthermore, through the use of persistent identifiers the digital editions can be sustainably referenced.

In keeping with the tradition of the $\mathrm{FiE}, \mathrm{CELSUS}$ is primarily focusing on a topographical approach since the geographic context of objects and the location of archaeological sites is often the first point of inquiry in archaeology. In the following I would like to illustrate several of the challenges we face in working with the geo-spatial information of Ephesos.

The FiE volumes contain a wide variety of spatial information. The most obvious sources are the maps contained in every volume of the $\mathrm{FiE}$. One of the first fairly precise maps of Ephesos was published in the first FiE in 1906 and was created by Hauptmann Anton Schindler. ${ }^{4}$ This map illustrates a first hurdle that we face in sorting our data: the map features several spelling variants and somewhat different terminology than that used in the text of the volume. The text and the map were created by two different people with differing objectives and academic backgrounds. Schindler created the map based on his training in geodesy and considerable interviews with locals while Benndorf's text approaches the landscape from a historic/archaeological viewpoint. In some instances the topographic terms are only

3 https://www.propylaeum.de/home/ (01.04.2019).

4 Otto Benndorf, Hg., Forschungen in Ephesos, Wien 1906. 
mentioned on this one map. Again, the text by Otto Benndorf refers to sites not indicated on the map. A lack of standardization in the geo-spatial terminology up until the 1960s has resulted in a multitude of terms. In a first step it will be necessary to resolve the geo-spatial terminology of the site. This includes extracting topographic terms from the digitized $\mathrm{FiE}$, particularly from the maps. The extracted terms will be fed into a geo-spatial database currently in development. The terms will be normalized to increase retrievability of information and reconciled with existing ontologies, such as Pleiades or the DAl gazetteer. This process will not only include the German concepts found in the main FiE-corpus but will also include English and Turkish variants. Through annotation of the geo-spatial references in the text it will be possible to move between text and geo-spatial database and identify information on specific locations more efficiently. This system provides the groundwork for the future interoperability of systems.

In collaboration with the Research Group Cartography of the TU Vienna we are working on semantically modeling the cartographic information on the topography of Ephesos so that we can take advantage of the information encoded in the maps and open up this documentation to further queries and knowledge extraction.

The second issue comes to play in later FiE publications, such as the standard site map illustrating the location of the archaeological sites. ${ }^{5}$ It nicely visualizes the amount of work that had been done in the 80 years since the first $\mathrm{FiE}$ publication and emphasizes the visitor path through Ephesos flanked by the many impressive reconstructions. ${ }^{6}$ The map is pragmatic: the amount of sites had become too dense so that the names could no longer be directly inserted into the map and instead numbers marked the sites. This map illustrates another issue of dealing with maps: they simply document the state of knowledge at the time of production of the map and are suggestive of ideal and neatly organized space but they do not indicate whether the monuments actually were contemporary. ${ }^{7}$ Not only is the time factor not reflected in this map but it also masks the complexity of individual locations. It is not able to show the development of a single site over centuries or millennia as would be necessary for a complex site like Ephesos.

The chronological factor will be an essential component of the project. On the one hand we will need to identify temporal terms as used by the various scholars but temporal terms only carry meaning if they are also defined. This means that it will be necessary to define the chronological terms used in the FiE through PeriodO $\mathrm{O}^{8}$ and include this in the encoding model of the texts. On the other hand we will also need to consider time in relationship to research history. An archaeological site is not only defined by the date of its creation, use, and abandonment but also by the time period when it was discovered, studied, published, reevaluated, ... We are currently investigating the possibility of modeling our data on the CIDOC-CRMarchaeo-model. ${ }^{9}$ Considering these actions not only in relationship to their geographic location but also to time will add another layer of information in reconstructing narratives of spaces and objects.

5 See the site plan in: Peter Scherrer, Ephesos. Der neue Führer, Wien 1995.

6 For more information on the evolution of the archaeological site of Ephesos, see: Sabine LADSTÄTTER, Ephesos: Archäologie und Massentourismus, in: Katja Piesker u. a., Hg., Heritage in Context 2. Archäologie und Tourismus, Miras 4, Istanbul 2018, 253-288.

7 Mark Gillings / Piraye HacigüzelleR / Gary Lock, Hg., Re-Mapping Archaeology: Critical Perspectives, Alternative Mappings, New York (2018), 1-16.

8 http://perio.do/en/ (01.04.2019).

9 http://www.cidoc-crm.org/crmarchaeo/home-3 (01.04.2019). 
A third complication in the geo-spatial data can be identified in the modern archaeological publications. By the mid-1990s the archaeological exploration of Ephesos became more detailed in its documentation and careful excavation of sites according to layers. Modern archaeology emphasizes the relationship between finds and layer where finds were recovered leading to meticulously documentation. The documentation of layers often gives a better sense of the scrappy realities of the built environment (construction, abandonment of sites, frequency of renovations, disrepair, and unfinished construction) but these illustrations are typically detached from maps, at least in their analog published form. Merging maps with the documented layers would provide a third dimension to understanding sites not only as separate monuments but as a continually evolving network of structures embedded into the wider development of a site. This would make it possible to not only explore the history of a single location over time but by including this third dimension the data could be visualized in more stimulating ways and lead to the identification of patterns that would otherwise remain hidden.

An immediate result of the project will be the creation of digital facsimiles of the FiE for archival purposes as well as for referencing. We are also developing a workflow for the digitization and preparation of the metadata so that future publications can be added as structured data to the spatially driven archive in consistent quality. All concepts will have unique identifiers and will be included in the encoding of the digital FiE so that scholars can move freely between maps and text. Furthermore, the data will be available through secure long-term hosting and presentation of the data in a subject-specific repository. Finally, the digital editions will include annotations to geo-spatial information and the digital foundation for further geo-spatial modeling and linking with our GIS-system will be in place. Our highly ambitious long-term goal is to create a sustainable archaeological linked data network by transforming our existing databases into interoperable systems. By making the data machine readable we are ensuring that the work of our predecessors at Ephesos is not forgotten but instead that it is made available for reuse and included in the developing knowledge network. This will lead to the possibility of increasingly more complex research questions by connecting our datasets with other datasets but will also be an important aspect in order to minimize disciplinary and linguistic boundaries.

\section{Literature}

Otto Benndorf, Hg., Forschungen in Ephesos, Wien 1906.

http://www.cidoc-crm.org/crmarchaeo/home-3 (01.04.2019).

Mark GilLings / Piraye HACıgüZelleR / Gary Lock, Hg., Re-Mapping Archaeology: Critical Perspectives, Alternative Mappings, New York (2018), 1-16.

Sabine LAdSTÄTTER, Ephesos: Archäologie und Massentourismus, in: Katja Piesker u. a., Hg., Heritage in Context 2. Archäologie und Tourismus, Miras 4, Istanbul 2018, 253-288.

Sabine LADSTÄTTER, Hafen und Stadt von Ephesos in hellenistischer Zeit, in: Jahreshefte des Österreichischen Archäologischen Institutes 85 (2016), 233-272.

Ben MARWICK / Suzanne BIRCH, A Standard for the Scholarly Citation of Archaeological Data as an Incentive to

Data Sharing, in: Advances in Archaeological Practice 6/2 (2018), 125-143.

http://perio.do/en/ (01.04.2019).

https://www.propylaeum.de/home/ (01.04.2019).

Peter ScherRer, Ephesos. Der neue Führer, Wien 1995.

Adela Sовоткоva, Sociotechnical Obstacles to Archaeological Data Reuse, in: Advances in Archaeological Practice 6/2 (2018), 117-124. 